\title{
Carbon Nanotube-Perovskite-Composites as New Electrode Material
}

\author{
Anke Weidenkaff $^{1}$, Stefan G. Ebbinghaus ${ }^{1}$, Thomas Lippert ${ }^{2}$, Macarena J. Montenegro ${ }^{2}$, and Armin Reller ${ }^{1}$ \\ ${ }^{1}$ Solid State Chemistry, University of Augsburg, D-86159 Augsburg, Germany, \\ ${ }^{2}$ Dept. General Energy Research, Paul Scherrer Institute, CH-5232 Villigen, Switzerland
}

\begin{abstract}
In this paper we describe the synthesis and characterisation of $\mathrm{La}_{1-x} \mathrm{~A}_{\mathrm{x}} \mathrm{CoO}_{3}(\mathrm{~A}=\mathrm{Ca}, \mathrm{Sr})(0<\mathrm{x}<0,5)$ of different morphologies using pulsed laser deposition, ceramic methods and alternative soft-chemistry techniques. Furthermore the potential use of a $\mathrm{La}_{1-\mathrm{x}} \mathrm{Ca}_{\mathrm{x}} \mathrm{CoO}_{3} /$ carbon nanotube composite material for oxygen electrodes is discussed.
\end{abstract}

Keywords: perovskite, electrocatalysis, carbon nanotubes, La-cobaltates, nanocomposite

\section{INTRODUCTION}

The stability and efficiency of oxygen electrodes of metal - air batteries and alkaline fuel cells will be decisive for their technical realization. The redox processes at the electrode in the highly alkaline media are responsible for the short lifetime of conventional teflon-bonded carbon diffusion electrodes. The oxygen evolution and oxygen reduction reactions in alkaline electrolytes occur via a two- electron pathway involving the formation of intermediate peroxide ions and $\mathrm{OH}^{-}[1]$.

Perovskite type metal oxides $\left(\mathrm{ABO}_{3}\right)$ with a lanthanide ion in the A position and a transition metal ion in the $\mathrm{B}$ position are known to be low cost, stable and active electrocatalysts for practical applications in fuel cells and metal-air batteries [2,3,4]. Particularly lanthanum cobaltates, manganates, ferrates and nickelates show good catalytic properties for the peroxide decomposition [5] [6].

For the production of gas diffusion electrodes, calcium and strontium substituted rare earth cobaltate powders with perovskite structure are synthesised. To study the influence of the particles size and shape co-precipitation-, ceramic-, complexation- and microemulsion processes are applied. As perovskites are not highly conductive, high surface area carbon and teflon as binder has to be added for a functional composite electrode material. We prepared a carbon nanotube composite material by a catalytic hydrocarbon dissociation reaction on metal oxide particles. With the combination of the properties of the metal containing part and the carbon nanotubes in a carbon nanotube/metal oxide-composite the carbon/metal oxide interface as well as the chemical and thermal stability of the electrode material can be improved (as carbon nanotubes are known to be more stable than carbon black).

Since carbon itself is catalytically active for the oxygen reduction and evolution reaction as well, it is necessary to prepare additionally electrodes on inactive substrates and with well defined electrolyte/catalyst interfaces to study and compare the oxygen reduction/evolution reactions for different perovskites. In our experiments a modified pulsed laser deposition (PLD) technique with reactive gas pulses [7] is applied to grow dense crystalline La- cobaltate films on various substrates.

\section{EXPERIMENTAL}

Coarse powders of $\mathrm{Ca}$ - and $\mathrm{Sr}$ substituted La- cobaltates are produced at $1200^{\circ} \mathrm{C}$ with conventional solid state reactions. By mixing the components on the molecular level, the formation of the perovskite proceeds at lower temperatures. This can be achieved by the production of mixed metal nitrate crystals. Another way to mix the metal ions are co-precipitations in microemulsions [8]. By this method stable dispersions of aqueous droplets are serving as microreactors for the precipitation reaction. They are produced by stirring a mixture of oil phase, surfactants, and an aqueous phase. Two of these emulsions, one containing the metal nitrates and the other one the precipitation agent are mixed to form a homogeneous precipitate inside the micelles. In additional synthesis procedures metal complexes with organic ligands are prepared as precursors for the metal oxides. In the hydroxy carbon acid aided 
synthesis [9] [10] citric acid or tartaric acid is used as complexing agent. The precursors are calcined at temperatures between $600^{\circ} \mathrm{C}$ and $700^{\circ} \mathrm{C}$.

The $\mathrm{La}, \mathrm{Ca}$ - cobaltate films are grown on $\mathrm{MgO}$ and stainless steel substrates by PLD. The experimental set-up has been described previously in detail [11]. A rotating $\mathrm{La}_{0.6} \mathrm{Ca}_{0.4} \mathrm{CoO}_{3}$ target is ablated and deposition takes place on a preheated substrate.

For the production of the carbon nanotube/metal oxide composite material, perovskite powders or macrostructured agglomerates (textile templates) are coated with a citrate precursor containing the perovskite mixture with a slight excess of cobalt oxide $(<1 \%)$. The material is produced in a similar procedure as described in [12].

The structural analysis of the perovskite powders and composite materials is done by powder X-ray diffraction (XRD) data collected on a Seifert XRD 3003-TT diffractometer using $\mathrm{Cu}-\mathrm{K}_{\alpha}$ radiation. Structure and texture of the single crystalline films have been studied on a Siemens D5000 X-ray diffractometer with Bragg-Brentano geometry $\left(\mathrm{Cu} \mathrm{K} \mathrm{K}_{\alpha}\right.$ radiation). The apparatus is equipped with an Eulerian cradle for the sample orientation. X-ray pole figures were measured by rotating the sample around the $\varphi$ axis and tilting the sample along the $\chi$ axis during the measurements with a fixed detector position $(2 \theta)$.

The morphology of the samples was examined using a LEO Gemini 982 scanning electron microscope (SEM) equipped with a Röntec energy dispersive X-ray analysis (EDX) detector system. Transmission electron microscopic (TEM) studies and electron diffraction were performed on a Phillips CM 30 instrument equipped with EDX detector. The surface area is measured by the BET-method (Micrometrics ASAP 2000).

After preparation and characterisation of the perovskites, electrodes are produced and tested for their catalytic activity in an electrochemical treatment. The tests of the electrodes are performed during several charge and discharge processes [5] in a three electrode arrangement.

\section{RESULTS AND DISCUSSION}

The morphology of the perovskite particles depends strongly on the synthesis procedure. The products from the ceramic synthesis route are powders with a particle diameter of $>5 \mu \mathrm{m}$. The decomposition of the single crystalline mixed nitrates leads to well crystallised platelet-shaped particles as can be see on the electron micrograph (Fig. 1). The XRD and SAED pattern reveal a cubic cell with $\mathbf{a}$ in the range of $0,381 \mathrm{~nm}<\mathrm{a}<0,383 \mathrm{~nm}$ depending on the synthesis procedure and substitution on A-site. In the SAED pattern besides the cubic perovskite lattice reflections weak additional reflections are present indicative of a superstructural ordering [13] [14]. The EDX studies revealed (semiquantitatively) that the individual particles had the composition given by their chemical formula.
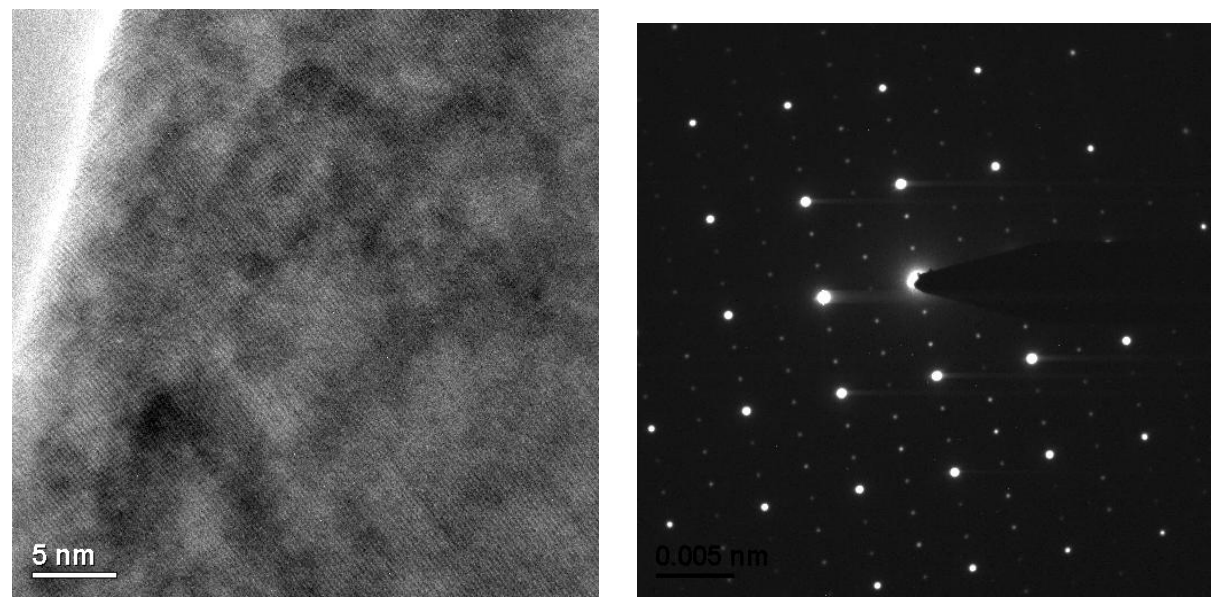

Fig. 1 : HRTEM and SAED od $\mathrm{La}_{0,6} \mathrm{Ca}_{0,4} \mathrm{CoO}_{3}$ particles from the decomposition reaction of La, Ca, Co-nitrate single crystals

The XRD and TEM characterisation of the single crystalline $\mathrm{La}_{0,6} \mathrm{Ca}_{0,4} \mathrm{CoO}_{3}$ films on $\mathrm{MgO}$ reveal that the oxide is growing epitaxially on the $\mathrm{MgO}$ substrate. The (200) and the (110) peaks of the product are the only non- 
substrate peaks appearing in the XRD $\Theta-2 \Theta$ scan at $\chi=0$ (see Fig. 2a). Therefore it can be concluded that the $\mathrm{La}_{0,6} \mathrm{Ca}_{0,4} \mathrm{CoO}_{3}$ is preferentially orientated along the (200) direction of the $\mathrm{MgO}$.

Figure $2 \mathrm{~b}$ shows the (111) pole figure of the $\mathrm{La}_{0,6} \mathrm{Ca}_{0,4} \mathrm{CoO}_{3}$-film at a $2 \theta$ angle at $42,97^{\circ}$. In the figure four maxima at $\chi=54^{\circ}$ are visible, indicative of the single crystalline domains of the orientated film.
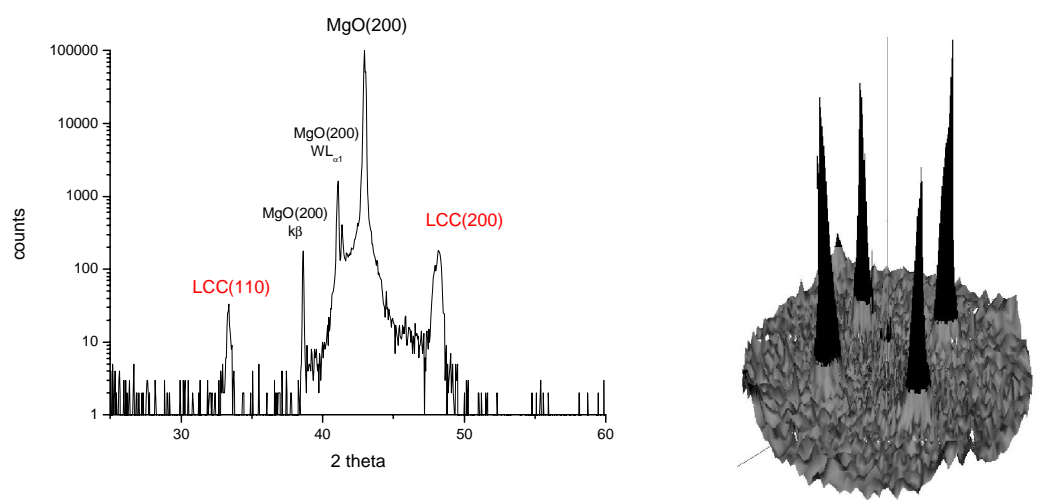

Fig. 2: XRD pattern (a) and 111 pole figure (b) of the $\mathrm{La}_{0,6} \mathrm{Ca}_{0,4} \mathrm{CoO}_{3}$ film on $\mathrm{MgO}$

TEM studies are performed to obtain detailed information on the local structure of the $\mathrm{La}_{0,6} \mathrm{Ca}_{0,4} \mathrm{CoO}_{3}(\mathrm{LCC})$ films on $\mathrm{MgO}$. The HRTEM image shown in Fig.3 represents the $\mathrm{MgO}$ substrate (upper part) and the $\mathrm{La}_{0,6} \mathrm{Ca}_{0,4} \mathrm{CoO}_{3}$-film (lower part).

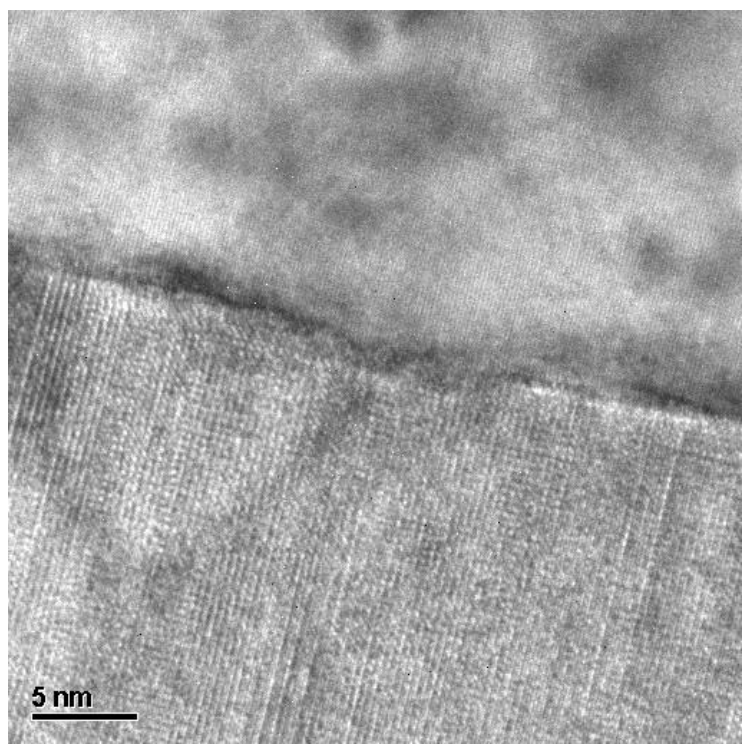

Fig. 3: HRTEM study of the $\mathrm{La}_{0,6} \mathrm{Ca}_{0,4} \mathrm{CoO}_{3}$ film on $\mathrm{MgO}$

The aim of this work is to optimise the electrode material by increasing its reactivity. Therefore the reactivity of the produced compounds is tested in two different processes: The catalysis of a hydrocarbon cracking reaction to form carbon nanotubes and the electrocatalytic performance in for oxygen evolution and reduction.

$\mathrm{La}_{1-\mathrm{x}}(\mathrm{Ca}, \mathrm{Sr})_{\mathrm{x}} \mathrm{CoO}_{3}$ and the amorphous precursors of these compounds are used as catalysts for the growth of carbon nanotubes. The nanoclusters of cobalt formed on the surface of the perovskite particles during the nanotube growth are suitable nucleation sites for the growth of nanotubes. The reactivity towards hydrocarbon cracking for the applied cobaltates varies from a CNT growth rate of nearly 0 to a rate of 90 weight $\%$ per minute. The composition and texture of the catalyst decides upon product quality and yield. Nanoparticles from the amorphous precursor process or the precursors themselves produce more carbon nanotubes than coarse products from ceramic synthesis. Furthermore it was found that Ca substituted La- cobaltates are more active than Sr-substituted or pure 
$\mathrm{LaCoO}_{3}$ demonstrating that the average A-cation radius and the cation-size mismatch affects the catalytic properties of the cobaltates significantly. Ca- ions are smaller than $\mathrm{La}$ - and $\mathrm{Sr}$ ions. Therefore Ca-substituted La-cobaltates are probably less stable (Goldschmidt-factor) than their Sr-substituted analogues. To study the influence of the electronic and crystallographic structure on the catalytic reactions combined Rietveld and EXAFS investigations [15] are in progress.

The TEM and SEM images of the products reveal that the formed multiwalled carbon nanotubes (MWNTs) have a length of approximately $20 \mu \mathrm{m}$ (see Fig.5) and diameters in the range of 20-30 nm. Some of the encapsulated particles were identified as metallic Co by EDX point analysis and EXAFS measurements. The data show clearly that during the reaction, the perovskite structure was partially destructed.
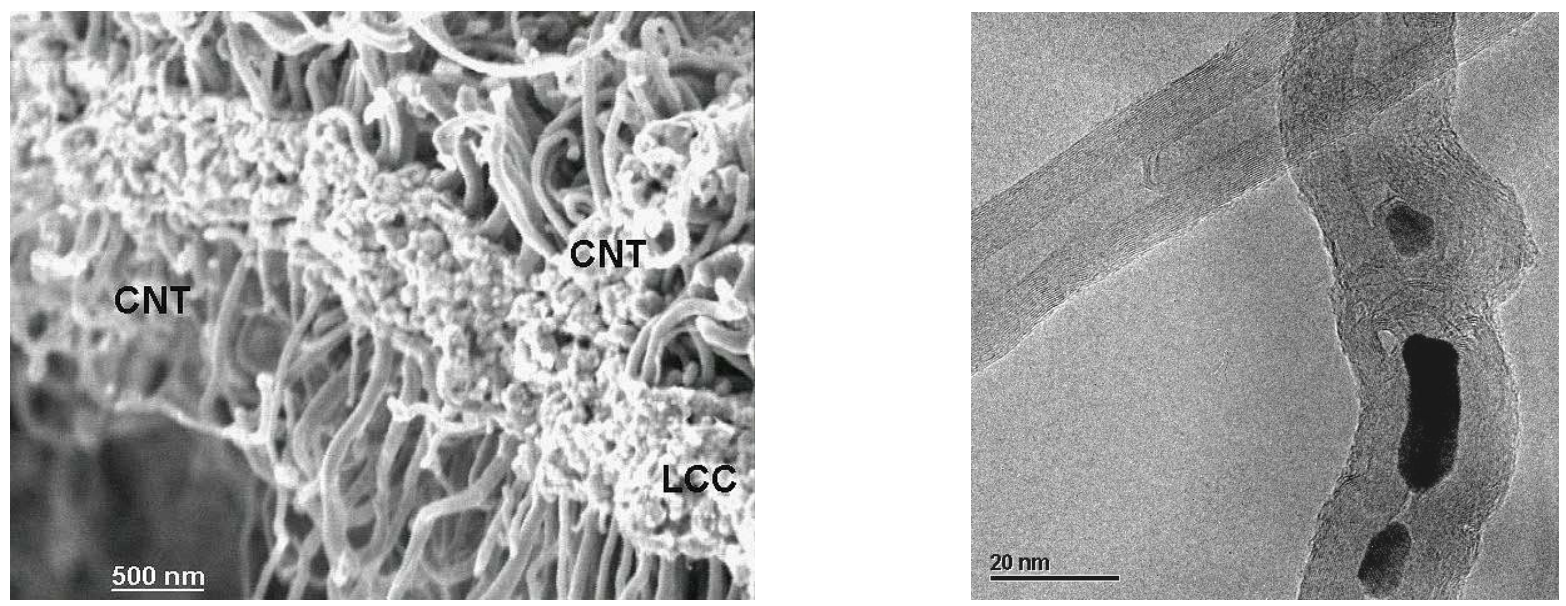

Fig. 5: SEM and TEM pictures of the LCC-CNT nanocomposite material

In additional experiments, perovskite particles are impregnated in advance with a precursor solution containing the appropriate stoichiometric citrate mixture with an excess of $5 \%$ cobalt. The excess Co in the sacrifying layer forms the nucleation sites for the carbon nanotube formation and prevents the bulk perovskite phase from decomposition. With these precursors it is possible to grow carbon nanotubes only on the surface of the particles in a very short reaction time ( $3 \mathrm{~min})$.

First tests with air electrodes consisting of 50 weight $\%$ multiwalled carbon nanotubes enclosing 50 weight $\%$ metal and metal oxide nanoparticles showed a comparable performance to state-of-the-art electrodes developed at PSI.

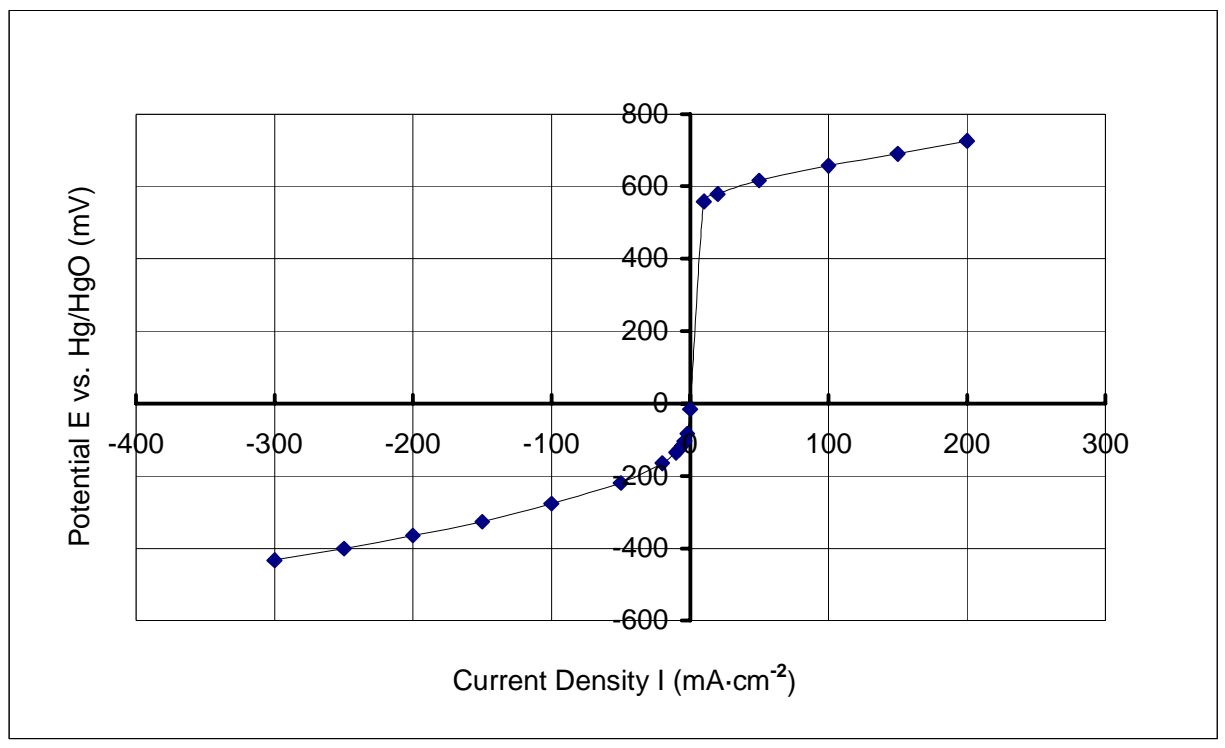

Fig. 6: Electrode Performance of the LCC-CNT material 
Consequently these new composite materials are highly interesting candidates for technical applications in oxygen electrodes.

\section{ACKNOWLEDGEMENTS}

The authors would like to thank Stefan Müller, PSI for inspiring discussions, Roland Wessiken, ETH Zürich for his help in the transmission microscopic studies, Andreas Heinrich, Universität Augsburg for helping to do the XRD-measurements of the films, Frederike Geiger, PSI Villigen for the BET measurements, Gertraud Masanz, PSI for the production of the electrodes, and Franziska Holzer, PSI for the measurements on the electrodes.

\section{REFERENCES}

1. V. Hermann, D. Dutriat, S. Müller, and Ch. Comninellis, Electrochimica Acta, 46, 365-372, (2000).

2. A. Martinez-Juarez, L. Sanchez, E. Chinarro, P. Recio, C. Pascual, and J. R. Jurado, Solid State Ionics, 135, 525$528,(2000)$.

3. A. J. McEvoy, J.Mater.Sci., 36, 1087-1091, 2001.

4. Y. Ohno, S. Nagata, and H. Sato, Solid State Ionics, 9\&10, 1001-1008, (1983).

5. S. Müller, K. Striebel, and O. Haas, Electrochimica Acta, 39, 1661-1668, (1994).

6. M. Bursell, M. Pirjamali, and Y. Kiros, Electrochimica Acta, 47, 1651-1660, (2002).

7. M. J. Montenegro, T. Lippert, S. Müller, A. Weidenkaff, P. R. Willmott, and A. Wokaun, Appl. Surf. Science, in press (2002).

8. A. Weidenkaff, S. Ebbinghaus, and T. Lippert, Chem.Mater., in press (2002).

9. M. S. G. Baythoun and F. R. Sale, J.Mater.Sci., 17, 2757-2769, (1982).

10. Y. Teraoka, H. Kakebayashi, I. Moriguchi, and S. Kagawa, Chemistry Letters, 673-676, (1991).

11. M. J. Montenegro, T. Lippert, S. Müller, A. Weidenkaff, P. R. Willmott, and A. Wokaun, Phys.Chem.Chem.Phys., in press (2002).

12. A. Weidenkaff, S. Ebbinghaus, P. Mauron, A. Reller, Y. Zhang, and A. Züttel, Materials Science and Engineering C, 19, 119-123, (2001).

13. A. Baiker, P. E. Marti, P. Keusch, E. Fritsch, and A. Reller, J.Catal., 146, 268-276, (1994).

14. R. H. E. van Doorn and A. J. Burggraaf, Solid State Ionics, 128, 65-78, (2002).

15. S. G. Ebbinghaus, A. Weidenkaff, and R. J. Cava, J.Solid State Chemistry, in press (2002). 